\title{
REFORMULASI GARIS-GARIS BESAR HALUAN NEGARA (GBHN) DAN AMANDEMEN ULANG UNDANG-UNDANG DASAR
}

\author{
Bambang Sadono ${ }^{1}$, Lintang Ratri Rahmiaji* ${ }^{2}$ \\ ${ }^{1}$ Fakultas Hukum Universitas Semarang, J1. Soekarno-Hatta Semarang \\ ${ }^{2}$ Fakultas Ilmu Sosial dan Ilmu Politik, Universitas Diponegoro, Jl. Prof. Soedarto, S.H. \\ Tembalang, Semarang \\ lintangratri84@gmail.com
}

\begin{abstract}
The GBHN reformulation discourse and the restoration of the MPR's authority to make provisions, strengthened again after the V PDI-P Congress (2019). The congress produced 23 recommendations containing party attitudes and policies as well as proposals for the administration of Jokowi-Ma'ruf 2019-2024. This study aims to map the political process the GBHN reformulation discourse and the position of the MPR after the 1945 Constitution Amendments. The results of this study found facts as a market leader in structuring the constitutional system by strengthening the MPR and setting the direction of the state, PDI-P is less skilled at managing the political situation. PDI-P, which is fighting for a limited agenda in the amendment, must tolerate another agenda. At present the power is in the leadership of the PDI-P and the president, but it also depends on the response of other large shareholders to the republic, namely the party chairmen who have representatives in the DPR/MPR.
\end{abstract}

Keywords: Reformulation; GBHN; MPR; Amandment; Constitution

\begin{abstract}
Abstrak
Wacana reformulasi GBHN dan pengembalian kewenangan MPR untuk membuat ketetapan, kembali menguat pasca-Kongres V PDI-P (2019). Kongres tersebut menghasilkan 23 rekomendasi yang berisi sikap dan kebijakan partai serta usulan untuk pemerintahan JokowiMa'ruf 2019-2024. Kajian ini bertujuan memetakan proses politik wacana reformulasi GBHN dan Posisi MPR pasca-amandemen UUD 1945. Hasil kajian ini menemukan fakta sebagai market leader dalam penataan sistem ketatanegaraan dengan memperkuat MPR dan menetapkan haluan negara, PDI-P kurang piawai mengelola situasi politik. PDI-P yang memperjuangkan agenda terbatas dalam amandemen, harus menenggang agenda lain. Saat ini kuasa ada di pimpinan PDI-P dan presiden, selain itu juga bergantung pada respon pemilik saham besar lain atas republik ini, yakni para ketua umum partai yang punya wakil di DPR/MPR.
\end{abstract}

Kata Kunci: Reformulasi; GBHN; MPR; Amandemen; Undang-Undang Dasar

\section{A. Pendahuluan}

Wacana reformulasi Garis-garis Besar Haluan Negara (GBHN) dan pengembalian kewenangan Majelis Permusyawaratan Rakyat (MPR) untuk membuat ketetapan, kembali menguat pasca-Kongres $\mathrm{V}$ Partai Demokrasi Indonesia Perjuangan (PDI-P) di Bali, 8-10 Agustus 2019 (Tempo.Co, 2019). Kongres tersebut menghasilkan 23 rekomendasi yang berisi sikap dan kebijakan partai serta usulan untuk pemerintahan Jokowi-Ma'ruf 2019-2024. Dari 23 rekomendasi tersebut, antara lain PDI-P mengusulkan agar tetap dilakukan amandemen terbatas Undang-Undang Dasar Negara Republik Indonesia Tahun 1945 (UUD 1945) untuk menetapkan kembali MPR sebagai lembaga tertinggi negara 
dengan kewenangan menetapkan Garisgaris Besar Haluan Negara (GBHN) sebagai pedoman penyelenggaraan pemerintahan. Hal ini dinilai diperlukan demi menjamin kesinambungan pembangunan nasional.

Penggunaan istilah GBHN, ditambah dengan MPR sebagai lembaga tertinggi ternyata membuat banyak kesalahpahaman. Pengkajian yang dilakukan oleh Badan Pengkajian MPR periode 2014-2019, berdasarkan Keputusan MPR RI No. IV/MPR/2014 tentang Rekomendasi Majelis Permusyawaratan Rakyat Republik Indonesia Masa Jabatan 2009-2014, yang berisi 10 rekomendasi, menggunakan terminologi yang agak berbeda. Poin kesepuluh rekomendasi MPR 2009-2014 tersebut lengkapnya berbunyi "melakukan reformulasi sistem perencanaan pembangunan nasional dengan model GBHN sebagai haluan penyelenggaraan negara". Kata "reformulasi" dan "model" sebenarnya merupakan kata kunci bahwa yang disadari sejak MPR 2009-2014 tersebut adalah kebutuhan haluan negara seperti GBHN, jadi bukan menghidupkan kembali GBHN.

Sedangkan yang menyangkut penataan kembali MPR, merupakan rekomendasi kedua yang berbunyi "penguatan MPR sebagai lembaga negara yang mempunyai kewenangan tertinggi dalam mengubah, menetapkan, menafsirkan Undang-Undang Dasar, dan memberikan arah kebijakan kepada lembaga-lembaga negara lainnya". Jadi tidak menyebut ingin mengembalikan MPR sebagai lembaga tertinggi. Bahkan istilah lembaga tertinggi juga tidak pernah ditemukan pada naskah UUD 1945 sebelum diamandemen.

Kesalahpahaman dimulai dari Ginandjar Kartasasmita (Kartasasmita, 2019), yang antara lain menulis "diskursus tentang keinginan mengembalikan GBHN disebabkan lebih pada nostalgia ke masa lalu yang dirasa lebih memberi kepastian pada arah dan proses pembangunan". Dan di bagian lain juga menulis "mengembalikan ke sistem yang berlaku di masa lalu dapat diartikan sebagai upaya mengembalikan sistem otokratis, anti demokrasi dan sentralistik".

Zainal Arifin Mochtar (Mochtar, 2019) berpendapat "sebenarnya, perubahan itu sendiri suatu keniscayaan, tetapi perlu demarkasi jelas, mana yang merupakan hal penting demi kepentingan bangsa dan mana yang hanya jualan politik". Perlukah kita melakukan amandemen? Banyak hal yang perlu diperbaiki, antara lain kejelasan sistem presidensial dan parlementer. Termasuk di dalamnya posisi Majelis Permusyawaratan Rakyat (MPR), Dewan Perwakilan Rakyat (DPR), dan Dewan Perwakilan Daerah (DPD) RI. Yang mengherankan bagi Zainal, mengapa dari sekian banyak usulan dan urgensi perbaikan konstitusi, yang disasar malahan hanya soal GBHN dan posisi MPR.

Mochtar Pabotinggi (Pabotinggi, 2019), antara lain menulis "beda dengan hajat rasional amandemen kelima untuk memperkuat DPD di sekitar 2006, hajat amandemen kelima kali ini didasari hasrat irasional agar MPR kembali jadi lembaga tertinggi negara yang menetapkan GarisGaris Besar Haluan Negara (GBHN). Kita mengetahui UUD 1945 memang masih perlu sejumlah amandemen penting, tapi jelas tak dalam kerangka irasionalitas politik".

Dari pendapat Ginandjar, Zainal, dan Mochtar tersebut, mengisyaratkan bahwa perbaikan sistem ketatanegaraan, bahkan melalui amandemen UUD RI 1945, bukan hal yang tidak mungkin. Bahkan Zainal menyebut ada beberapa hal yang urgen dalam sistem ketatanegaraan kita yang membutuhkan amandemen kelima UUD RI 1945. Seperti yang dikemukakan oleh Mahfud (Mahfud MD, 2010), walaupun amandemen sebelumnya telah memperbaiki banyak hal dalam sistem ketatanegaraan, tetap harus dibuka peluang untuk amandemen lagi agar lebih sempurna, asal dilakukan dengan prosedur yang konstitusional.

Hanya agenda mengembalikan sistem perencanaan pembangunan model GBHN dan mengembalikan kewenangan MPR membuat ketetapan regeling, sekaligus 
mengembalikan posisinya sebagai lembaga tertinggi negara, banyak disalahpahami. Jika dibandingkan dengan kesimpulan pengkajian di MPR, tampak ada persepsi yang berbeda antara apa yang dirumuskan MPR, dan apa yang dibayangkan oleh publik pada umumnya.

Pertanyaan selanjutnya, mengapa dari sekian banyak agenda yang dipilih dan ditonjolkan hanya soal haluan negara atau GBHN, dan posisi MPR RI. Apakah ini benar benar kepentingan publik, atau sekadar kepentingan politik? Pertanyaan lain mengapa posisi MPR pasca-amandemen UUD 1945 menimbulkan kontroversi dalam sistem ketatanegaraan kita.

\section{B. Pembahasan}

\section{Bukan GBHN Tetapi Haluan Negara}

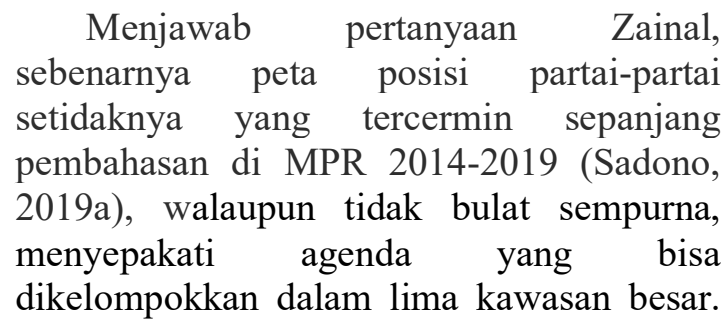

Pertama, revitalisasi Pancasila dan penegasannya sebagai dasar dan ideologi negara serta posisinya sebagai sumber tertib hukum; kedua reformulasi Sistem perencanaan pembangunan model GBHN; ketiga penataan lembaga MPR; keempat penataan lembaga DPD RI, dan kelima penataan lembaga kekuasaan kehakiman. Dari kelima agenda tersebut, memang reformulasi GBHN dengan sekaligus memberi kewenangan pada MPR untuk menetapkannya, menjadi pilihan terbanyak fraksi-fraksi, dengan segala variannya.

Ibarat sajian menu makanan model prasmanan, reformulasi model GBHN tersebut yang memang mendapat respon politik terkuat, apalagi dengan dukungan partai dengan kursi terbanyak di parlemen, PDI Perjuangan. Sejak awal PDI-P memang memasang syarat agar kalau ada amandemen kelima terhadap UUD RI 1945 hanya dilakukan untuk agenda reformulasi sistem GBHN dan penguatan lembaga MPR. Di sinilah muncul perbedaan dan variasi pendapat di antara fraksi-fraksi dan kelompok DPD RI di MPR.

Secara teori, mengenai pilihan pilihan itu memang sepenuhnya tergantung pada otoritas politik yang berwenang untuk itu. Dalam pemilihan agenda amandemen undang-undang dasar merupakan kewenangan MPR RI. Menurut Hans Kelsen (Kelsen, 1996), hukum lebih berkepentingan bagaimana undang-undang itu dibuat apapun materinya, bukan pada bagaimana seharusnya dia dibuat, dan apa yang seharusnya dimuat dalam undang-undang tersebut "what the law is, and how the law is made, not the questions of what the law ought to be or the law ought to be made". Selebihnya memang sepenuhnya pilihan politik.

Dalam melaksanakan politik hukum berdasarkan Pancasila itulah menurut Kaelan (Kaelan, 2014) jika memungkinkan dilakukan amandemen terhadap UUD RI 1945, dengan mengembalikan kewenangan MPR untuk menetapkan GBHN. Pilihan ini mencerminkan prinsip demokrasi terutama dalam hubungannya dengan sila kerakyatan yang dipimpin oleh hikmat kebijaksanaan dalam permusyawaratan/perwakilan. Meskipun presiden dan DPR dipilih secara langsung oleh rakyat, penyusunan rencana pembangunan nasional harus dilaksanakan oleh rakyat, dan MPR yang merepresentasikan kekuasaan rakyat.

Salah satu penyebab mengapa muncul kesalahpahaman semacam itu, karena proses pengkajian di MPR, tidak terkomunkasikan dengan baik. Sebenarnya sikap fraksi dan Kelompok DPD di MPR menyangkut kajian reformulasi sistem perencanaan pembangunan model GBHN tersebut bisa dikelompokkan dalam tiga skenario (Sadono, 2019b).

Skenario pertama, memberikan kewenangan kepada MPR untuk menetapkan GBHN. Skenario kedua, GBHN ditetapkan melalui undang-undang. Skenario ketiga, sebagai jalan tengah, GBHN dipecah menjadi dua, haluan negara sebagai kaidah penuntun secara makro, 
menurut istilah lain disebut state policy, ditetapkan oleh MPR, yang berupa sistem perencanaan pembangunan nasional (SPPN) dalam undang-undang. Haluan negara meliputi perencanaan dengan jangka waktu yang lebih jauh dan meliput semua aspek kehidupan bernegara, sedangkan SPPN dengan jangka waktu yang lebih terbatas dan fokus pada pembangunan perekonomian.

Ada juga yang menginginkan materi GBHN dimasukkan ke dalam rumusan pasal-pasal Undang-Undang Dasar. Pertimbangannya menurut Susi Dwi Harijanti (Hariyanti, 2016) beberapa negara memasukkan haluan negara dalam konstitusinya. Konstitusi Irlandia sejak 1937 telah mencantumkan Directive Principle of State Policy yang berisikan panduan kebijakan ekonomi, mekanisme pasar bebas, intervensi negara dan lain-lain. Sejak itu, banyak negara yang mengikuti seperti Belgia, India, Nepal, Pakistan, Filipina, Afrika Selatan dan lain-lain.

Haluan Negara yang kemudian disepakati, merupakan peta jalan (road map) seluruh bangsa dan negara juga mencakup seluruh bidang. Baik ekonomi, politik, sosial, maupun budaya. Program diterjemahkan dari ideologi bangsa dan konstitusi negara. Karena merupakan garisgaris besar, Haluan negara akan dibuat sebagai dokumen yang ringkas, sekaligus sedapat mungkin jelas dan bernas. Hal-hal detail akan diterjemahkan dalam program setiap lembaga negara. Khusus haluan pembangunan akan didetailkan oleh presiden dan jajaran pemerintah, termasuk pemerintah daerah.

Haluan negara harus menjawab arah besar yang akan dicapai bangsa ini 50 sampai 100 tahun ke depan, misalnya memilih akan menjadi negara pertanian, maritim, atau industri, gabungan ketiganya, atau penggabungan secara bertahap. Baru kemudian pendetailan program jangka pendek melalui haluan pembangunan yang lebih luwes dan praktis, seperti GBHN pada masa Orde Baru.

Berbeda dengan yang dipersepsikan oleh banyak kalangan, setidaknya oleh
Ginandjar dan Mochtar Pabotinggi, yang akan dirumuskan dan ditetapkan oleh MPR RI 2019-2024 jika kesepakatan politiknya terjadi, bukan GBHN seperti yang pernah dibuat dan dijalankan pada masa pemerintahan Presiden Soeharto, atau yang sering disebut era Orde Baru. GBHN selama Orde Baru sudah menjadi nama, bukan seperti rumusan UUD 1945 sebelum amandemen, yang merupakan peta atau cakupan yang lebih luas tidka sekadar program pembangunan yang harus dilaksanakan oleh presiden.

Pentingnya haluan negara, juga dikemukakan oleh Yudi Latif (Latif, 2016), yang menyatakan tujuan nasional seperti yang tercantum dalam pembukaan UUD 1945 haruslah bersandar pada tiga konsensus fundamental, yakni Pancasila sebagai falsafah dasar, UUD sebagai hukum atau norma dasar, dan haluan negara sebagai kebijakan dasar.

Bahkan negara maju seperti Amerika Serikat juga disarankan agar mempunyai strategi dan perencanaan jangka panjangnya. George Friedman (Friedman, 2011), penulis buku The Next 100 Years, dalam bukunya The Next Decade, juga menyarankan agar dipersiapkan bentuk negara sesuai dengan peran yang akan dimainkan, yang akan membuat Amerika bukan lagi sebagai republik dengan yurisdiksi seperti sekarang ini, tetapi bisa jadi akan menjadi semacam American Empire, kekaisaran Amerika. Termasuk merencanakan pemimpin yang cocok dengan bentuk negara yang tidak pernah dibayangkan dan diharapkan tersebut. Termasuk juga memprediksi "forecast of the world in wich we will be living during this decade".

\section{Bukan Lembaga Tertinggi, Kewenangan Tertinggi}

Kesalahpahaman terhadap gagasan PDI$P$ untuk mengembalikan status MPR sebagai lembaga tertinggi negara, sebenarnya bukan sesuatu yang esensial, hanya merupakan perdebatan yang emosional, karena berkalikali muncul dalam pidato ketua umum PDIP Megawati Soekarnoputeri. Selama ini 
istilah lembaga tertinggi negara juga hanya merupakan tafsir, karena sebelum diamandemen UUD 1945 mengatur bahwa MPR merupakan pelaksana kedaulatan rakyat, dan mempunyai kewenangan untuk memilih presiden dan wakil presiden.

Memang telah terjadi inkonsistensi dan inkoherensi konsep kedaulatan rakyat dalam UUD stealah diamandemen. Dalam UUD RI 1945 hasil amandemen ditentukan dalam Pasal 1 Ayat (2) bahwa "kedaulatan berada di tangan rakyat dan dilaksanakan menurut Undang-Undang Dasar". Kemudian keterwakilan rakyat antara lain dirumuskan dalam Pasal 2 Ayat (1) UUD 1945 "Majelis Permusyawaratan Rakyat (MPR) terdiri atas anggota Dewan Perwakilan Rakyat (DPR) dan anggota Dewan Perwakilan Daerah (DPD)". Itu menunjukkan bahwa pascaamandemen UUD 1945, keterwakilan rakyat terdiri atas perwakilan politik (political representation) yakni DPR RI dan perwakilan daerah (regional representation) yakni DPD RI. Namun dalam pasal-pasal lebih lanjut tidak mengatur mengenai posisi ketiga lembaga strategis ini lebih detail, terutama inter-relasi ketiga lembaga tersebut. Menurut Kaelan (Kaelan, 2017), ketidakjelasan keterwakilan rakyat dalam sistem ketatanegaraan menurut UUD 1945 pasca-amandemen didasari oleh semangat untuk meniadakan kedaulatan rakyat yang ada dalam MPR melakukan take over begitu saja konsep check and balances, serta dendam terhadap kekuasaan Orde Baru yang meletakkan kedualatan rakyat dalam satu lembaga tertinggi MPR.

Akibatnyanya muncullah tafsir, bahwa ketiga lembaga negara ini posisinya sejajar, bahkan juga sejajar dengan presiden, Mahkamah Agung (MA), Badan Pemeriksa Keuangan (BPK), Mahkamah Konstitusi (MK), dan Komisi Yudisial (KY). Jimly Asshiddiqie (Asshiddiqie, 2009) menyebut bahwa setelah perubahan UUD 1945, tidak dikenal lagi konsepsi lembaga tertinggi dan tinggi negara. Lembaga-lembaga negara yang merupakan organ konstitusional tidak lagi seluruhnya hierarkis di bawah MPR tetapi sejajar dan saling berhubungan sesuai dengan kewenangan masing-masing berdasarkan UUD 1945. Jimly mencatat ada 34 lembaga negara yang disebut dalam UUD 1945, termasuk menteri, kepolisian, Bank Indonesia, dan pemerintah daerah. Dari 34 lembaga negara itu ada yang digolongkan sebagai lembaga tinggi untuk lapis pertama, sedangkan lapis kedua disebut lembaga negara saja, dan lapis ketiga disebut lembaga daerah.

Pertanyaan muncul (Sadono, 2019c), mengapa Jimly tidak mengaitkan dengan teori kedaulatan rakyat yang antara lain diwujudkan secara terang benderang melalui sistem pemilihan umum? Hanya tiga lembaga yang dipilih langsung oleh rakyat, yakni presiden/wakil presiden, DPR RI, dan DPD RI. Mengapa lembaga yang jelas-jelas mendapat mandat langsung dari rakyat, disejajarkan dengan lembaga yang dibentuk sebagai turunan dari lembaga pemegang kedaulatan rakyat tersebut? Bukankah MK, MA, dan BPK merupakan lembaga yang dibentuk presiden, DPR, dan ada yang dengan pertimbangan DPD.

Seperti yang disimpulkan oleh Ramlan Surbakti (Surbakti, 2010), "bagi sementara sistem politik, penyelenggaraan pemilihan umum dianggap cukup untuk menunjukkan pemerintahannya memiliki legitimasi”.

Dimana posisi yang tepat untuk MPR? Dalam Pasal 2 Ayat 1 UUD 1945 diatur "MPR terdiri atas anggota DPR dan anggota DPD yang dipilih melalui pemilihan umum dan diatur lebih lanjut dengan undangundang”. MPR merupakan gabungan dari dua lembaga tinggi negara (istilah Jimly) yang secara logika posisinya pasti harus di atas kedua lembaga yang bergabung tersebut. Adapun jika dilihat dari segi kewenangan, Pasal 3 Ayat 1 UUD RI 1945 mengatur, "MPR berwenang mengubah dan menetapkan undang undang dasar".

UUD merupakan dokumen hukum tertinggi yang mengatur sebuah negara. Untuk menetapkan dan mengubahnya diserahkan kepada MPR, sehingga kemudian ada yang menyebut MPR merupakan lembaga negara dengan kewenangan tertinggi. Karenanya tafsir 
MPR sama dan sejajar dengan lembaga negara yang lain, apalagi disetarakan dengan MK, MA, dan BPK menimbulkan kontroversi tersendiri, baik secara teori maupun praktik. Inilah yang kemudian membuat Megawati Soekarnoputri (Republika, 2018), berpendapat kedudukan MPR RI sejajar dengan lembaga negara yang lain, tidak sesuai dengan pemikiran para pendiri bangsa.

Dalam realitas politik, walaupun tidak dinyatakan secara eksplisit, MPR juga sudah merupakan lembaga tertinggi negara. Pertama, terhadap lembaga kepresidenan, MPR punya kewenangan memakzulkan, tentu maknanya bahwa posisi MPR lebih tinggi kewenangannya daripada presiden, yang memakzulkan pasti harus lebih tinggi daripada yang dimakzulkan. Sebaliknya, presiden tidak mempunyai kewenangan untuk membubarkan MPR. Jika berhadapan dengan DPR atau DPD, MPR merupakan gabungan dari dua lembaga tersebut dengan legitimasi politik cukup kuat karena dipilih langsung oleh rakyat. Apalagi jika dihadapkan pada lembaga tinggi negara yang lain seperti BPK, MA, MK, dan KY yang pembentukannya dilakukan melalui DPR dan DPD.

Berdasarkan realitas tersebut, Kaelan (Kaelan, 2016) berpendapat bahwa berdasarkan kaidah sebagaimana terkandung dalam Pasal 2 UUD RI 1945, sebenarnya MPR memiliki kekuasaan lebih tinggi daripada presiden, DPR, dan DPD. Senada dengan hal tersebut, Fajrul Falaakh (Falaakh, 2009) mengemukakan bahwa dalam praktik, MPR mempunyai kedudukan lebih tinggi daripada lembaga lain, termasuk lembaga yudikatif. Menurut UUD RI 1945, MPR bisa menjatuhkan sanksi kepada presiden dalam kasus jika ada pelanggaran berat.

\section{Kemungkinan Amandemen Kelima}

K.C. Wheare menyebutkan merupakan resultante dari keadaan politik, ekonomi, sosial, dan budaya (Poleksosbud) ketika konstitusi dibuat. Konstitusi menggambarkan kebutuhan dan jawaban atas persoalan yang dihadapi saat itu (Baital, 2014). Konstitusi merupakan hasil dari kepentingan seluruh warga bangsa, dengan kata lain hukum merupakan produk politik. Mahfud M.D. (Mahfud MD, 2017) menegaskan jika hukum dikonsepkan sebagai undang-undang yang dibuat lembaga legislatif, tidak ada yang bisa membantah bahwa hukum sebagai produk politik. "Ia merupakan kristalisasi, formalisasi, atau legalisasi dari kehendakkehendak politik, yang saling bersaingan baik melalui kompromi politik, maupun melalui dominasi oleh kekuatan politik yang terbesar". Hukum, termasuk konstitusi dihasilkan bukan karena pertimbangan benar-salah dan baik-buruk, tetapi karena kesepakatan para pembuatnya. Jadi perumusan maupun perubahan sebuah konstitusi, tergantung lembaga yang berhak untuk merubah dan menetapkannya.

Pada situasi kasus di Indonesia, otoritas ini berada pada lembaga MPR, yang sebagian besarnya yakni sejumlah 575 orang terdiri dari anggota DPR, dan selebihnya 136 anggota DPD. Karena itulah posisi DPR disini dapat dilihat sangat menentukan. Realitas secara politis, seluruh fraksi di DPR yang otomatis ada di MPR, tergantung arahan dari partainya masing-masing. Fraksi yang merupakan kepanjangan tangan dari partai, sudah tentu dikontrol oleh pimpinan, dan lebih ekstrimnya lagi dikendalikan oleh ketua umumnya masing-masing.

Jika dewasa ini sedang mengemuka wacana mengenai amandemen UUD 1945, utamanya mengenai reformulasi Garis-Garis Besar Haluan Negara (GBHN), pada akhirnya keputusan mengenai hal ini akan kembali kepada para pimpinan partai, contohnya terkait dengan keputusan diperlukannya amandemen atau tidak. Amandemen hanya dapat diusulkan oleh lebih dari sepertiga anggota MPR. Jika Partai Demokrasi Indonesia Perjuangan (PDI-P) mengajukan prakarsa atas usulan amandemen terbatas mengenai pemberian kembali kewenangan lembaga MPR untuk menetapkan GBHN, yang perlu dipalukan adalah berupaya mengajak anggota dari 
fraksi-fraksi lain atau kelompok DPD di MPR, sampai mendapatkan minimal dukungan sebanyak 238 anggota.

Apabila usulan amandemen sudah memenuhi ketentuan syarat secara prosedural, berikut agendanya disepakati, sekaligus akan menjawab perbedaan pendapat mengenai istilah terbatas. Terbatas disini bukanlah berarti kehendak dari satu atau beberapa fraksi, termasuk kelompok DPD, akan tetapi pemahaman terbatas ini adalah karena pengusul harus menyebut bagian yang ingin diubah, bagaimana bunyi perubahannya, dan bagaimana argumentasi atau urgensi atas perubahan tersebut. Apabila yang disepakati hanya terbatas mengenai GBHN dan pengembalian kewenangan MPR untuk menetapkan GBHN tersebut, maka itulah yang akan dibahas. Sehingga disini tidak memungkinkan adanya agenda baru selama pembahasan selain agenda tersebut. Oleh sebab itu, trauma kotak pandora, yang bisa menyebabkan pembahasan agenda amandemen melebar, secara yuridis konstitusional tidak dimungkinkan dan tidak perlu dirisaukan.

Dalam konteks usulan amandemen UUD untuk pengembalian GBHN oleh Fraksi PDI-P, sebenarnya bukan hanya karena rekomendasi Konggres PDI-P di Bali belum lama ini. Rapat Kerja Nasional (Rakernas) PDI-P, Januari 2016 sudah mengambil keputusan untuk mengadopsi gagasan Megawati Soekarnoputeri tersebut. Dalam berbagai kesempatan Megawati mengemukakan bahwa MPR merupakan lembaga negara yang memang khas Indonesia, yang didesain oleh para bapak bangsa sebagai model yang berbeda dari sistem yang sudah dikenal pada waktu itu, yakni sistem komunis atau sistem liberal, karena itu kewenangannya tidak boleh disejajarkan dengan lembaga negara yang lain.

Semua fraksi di MPR 2014-2019, sepakat untuk mempertimbangkan kemungkinan reformulasi sistem perencanaan pembangunan model GBHN. Ini tercermin dari laporan Badan Pengkajian
MPR yang sudah disampaikan dalam rapat gabungan 22 Agustus 2016. Isyarat itu sebelumnya juga disampaikan Ketua MPR RI Zulkifli Hasan saat sidang tahunan MPR 16 Agustus 2016, bahkan kemudian disambut baik oleh Presiden Joko Widodo. Dibutuhkan haluan negara untuk mengelola negara yang besar dan heterogen ini. Hanya keinginan untuk menjadikan pengembalian haluan negara tersebut sebagai amandemen yang terbatas belum memperoleh kesepakatan yang bulat.

Setelah agenda disepakati, dan pengusulan formal dilakukan, untuk memutuskan kuorum sidang paripurna harus dihadiri minimal $2 / 3$ anggota MPR. Sedangkan untuk mengambil keputusan setidaknya disetujui oleh 50 persen plus 1 dari anggota yang hadir.

Apapun yang akan diputuskan, menurut Made Subawa (Subawa, 2016) MPR ke depan hendaknya dapat merumuskan kajian model GBHN yang meletakkan dasar, arah, tujuan, dan tahapan pembangunan nasional. GBHN harus mensinkronkan tahapan Rencana Pembangunan Jangka Panjang Nasional (RPJPN), Rencana Pembangunan Jangka Menengah Nasional (RPJMN), dan Rencana Pembangunan Jangka Menengah Daerah (RPJMD), yang akan menjadi rujukan misi/visi calon presiden atau calon gubernur, dan bupati/walikota. Sisi baik perencanaan pembangunan nasional di masa lalu agar diambilkan untuk menyusun GBHN ke depan.

\section{Simpulan}

Pertanyaannya yang dapat diajukan adalah bagaimana kemungkinan dilakukan amandemen pada MPR 2019-2024? Mengapa PDI-P tidak mampu mempengaruhi fraksi-fraksi lain untuk meloloskan amandemen terbatas itu pada periode 2014-2019? Bahkan, meskipun sudah disampaikan oleh ketua MPR RI, Zulkifli Hasan perihal panitia ad hoc yang diketuai Ahmad Basarah (wakil ketua MPR RI) yang hendak melakukan pembahasan mengenai reformulasi GBHN pada 16 Agustus 2018 lalu. 
Posisi presiden sebagai pemimpin tertinggi eksekutif yang akan menjadi salah satu bahasan yang terpenting sebagai objek pengaturan konstitusi perlu diperhatikan. Meskipun secara konstitusional presiden tidak memiliki kewenangan untuk berperan secara langsung, akan tetapi secara politis, presiden tentunya memiliki pengaruh yang cukup besar.

Sebagai kesimpulan, sebagai market leader dalam penataan sistem ketatanegaraan dengan memperkuat posisi MPR dan menetapkan suatu haluan negara, PDI-P harus benar-benar pandai mengelola situasi politik, yang sepertinya juga mulai bergeser dari situasi tahun 2014-2019. Barangkali PDI-P yang memperjuangkan agenda tunggal atau terbatas dalam amandemen, juga mau tidak mau harus menenggang agenda lain, dengan catatan tidak terlalu ekstrim, misalnya sampai kepada upaya mengembalikan pemilihan presiden kepada MPR.

\section{DAFTAR PUSTAKA}

Asshiddiqie, J., Menuju Negara Hukum Yang Demokratis, Jakarta: Bhuana Ilmu Populer, pp. 457, 2009.

Baital, B., Pertanggungjawaban Penggunaan Hak Prerogatif Presiden Di Bidang Yudikatif Dalam Menjamin Kemerdekaan Kekuasaan Kehakiman, Jurnal Cita Hukum, vol. 2, no. 1, p. 22, 2014.

Falaakh, M. F., Menata Sistem Presidensial" Dalam, in Jalan Berliku Amandemen Komprehensif, Jakarta: DPD RI dan Citra Almamater, p. 45, 2009.

Friedman, G., The Next Decade, New York: Anchor Books, pp. 238-239, 2011.

Hariyanti, S. D., Merumuskan Ulang GarisGaris Besar Haluan Negara, Jurnal Majelis, vol. 4, p. 23, 2016.

Kaelan, Inkonsitensi dan Inkoherensi Dalam UUD NRI Tahun 1945 Hasil Amandemen (Kajian Filosogfis-
Yuridis), Jakarta: Badan Pengkajian MPR RI, pp. 122-123, 2017.

Kaelan, Kajian Kritis Kewenangan MPR, Jurnal Majelis, vol. 3, pp. 45-46, 2016.

Kaelan, Refomulasi Model GBHN Suatu Tinjauan Filosofis, Jurnal Majelis, vol. 2, p. 100, 2014.

Kartasasmita, G., Perlukah Kita Kembali Ke GBHN, Kompas, August 22, 2019.

Kelsen, H., Introduction to The Problems of Legal Theory, New York: Clarendon Paperbaks, pp. 7, 1996.

Latif, Y., Rancang Bangun GBHN, Kompas, August 30, 2016.

Mahfud MD, M., Perdebatan Hukum Tata Negara Pasca Amandemen Konstitus, Jakarta: Raja Grafindo Persada, xv, 2010 .

Mahfud MD, M., Politik Hukum Indonesia, Jakarta: Raja Grafindo Persada, pp. 5, 2017.

Mochtar, Z. A., Bola Salju Amandemen Kelima UUD 1945, Kompas, August 28, 2019.

Pabotinggi, M., Haluan Fatamorgana, Kompas, September 4, 2019.

Republika, Megawati Soroti Status Dan Kedudukan MPR, Republika.co.id, March 14, 2018.

Sadono, B., Amandemen GBHN Tergantung Pemimpin Partai, Kompas, September 6, 2019a.

Sadono, B., Penataan Sistem Ketatanegaraan, Jakarta: DPD RI dan Citra Almamater, pp. 160, 2019b.

Sadono, B., Penataan Sistem Ketatanegaraan, Jakarta: DPD RI dan Citra Almamater, pp. 178, 2019c.

Subawa, M., Penataan Kewenangan MPR RI Dan Sistem Perencanaan Pembangunan Nasional Model GBHN Berdasarkan Pancasila Dan UUD NRI Tahun 1945, 
Jurnal Majelis, vol. 3, p. 132, 2016.

Surbakti, R., Memahami Ilmu Politik, Jakarta: Grasindo, pp. 124, 2010.
Tempo.Co, Ada 23 Rekomendasi Kongres PDI-P, Dari GBHN Hingga UU Sisdiknas, Tempo.Co, August 10, 2019. 